\title{
Interprofessional student meetings in municipal health service: Mutual learning towards a Community of Practice in patient care
}

\begin{abstract}
Mutual engagement is fundamental in interprofessional collaboration. This paper investigated how mutual engagement evolves in interprofessional student meetings when medical, nursing, occupational therapy and physiotherapy students shape their own collaboration and learning in patient care. We conducted a qualitative study with an ethnographic design. The data material consists of 200 hours of observations across nine student groups and two informal conversations with each student group during a two-week clinical placement in the period of 2014 - 2015. The interprofessional student meetings and the informal conversations were audio recorded, and field notes were prepared from our observations of the student activities. In the data analysis, we relied on an interpretative thematic analysis and used the sociocultural theory of learning as an interpretative framework. The analysis showed that mutuality evolved through three types of mutual engagement: facilitating interactions, actual interactions and clarifying further interactions. In conclusion, complex mutual engagement in patient care evolved and was maintained in interprofessional student meetings when the students had an explicit opportunity to shape their own interprofessional collaboration and learning. The students' opportunity to shape the interprofessional collaborative practice in patient care themselves appeared to be a criterion for success.
\end{abstract}

Keywords: Interprofessional education, communities of practice, mutual engagement, interprofessional student meetings, field work. 


\section{Introduction}

For almost three decades, policymakers have invoked interprofessional education (IPE) in health education to prepare students for interprofessional collaborative practice when entering the workforce after graduation (CAIPE, 2010, 2017; Frenk et al., 2010; Reeves et al., 2016; WHO 2010). IPE occurs “... when students from two or more professions learn about, from and with each other to enable effective collaboration and improve health outcomes" (WHO, 2010, p. 7). The intent of IPE is to transform students into efficient team workers who deliver optimal health services (CAIPE, 2017; Reeves et al., 2016; WHO, 2010). Over the years, diverse IPE interventions have been conducted in many different countries and health care settings (Reeves, Palaganas \& Zierler, 2017; Reeves et al., 2016; WHO, 2010, p. 16). However, policymakers, leaders, practitioners, educators and researchers still seek knowledge about effective IPE to guide them in the planning and implementation of IPE (CAIPE, 2017; Reeves et al., 2017; Thistlethwaite, 2012).

Gaining knowledge about IPE effectiveness is a laborious process. There is vast diversity in IPE interventions; i.e., learning environment and activities, durations, numbers and mixes of disciplines (Olson \& Bialockerkowski, 2014; Reeves et al., 2016, 2017; Thistlethwaite, 2012), and a lack of studies on the effects of traditional professional education on learners' interprofessional collaborative competence (Reeves, Perrier, Goldman, Freeth\& Zwarenstein, 2013). Additionally, there is vast diversity in IPE research; i.e., research methods, methodologies and qualities (Olson \& Bialockerkowski, 2014; Reeves et al., 2017; Thistlethwaite, 2012). Nevertheless, the research community states that a comprehensive understanding of IPE and its effectiveness requires a meta-epistemological approach (Olson \& Bialocerkowski, 2014) that encompasses different paradigms, methodologies and methods 
(Olson \& Bialocerkowski, 2014; Reeves et al., 2016, 2017; Thistlethwaite, 2012). However, the methodology has to be rigorous to optimize the study quality (Foreman, Jones \& Thistlethwaite, 2016; Olson \& Bialocerkowski, 2014; Reeves \& Pauzé, 2010a; Reeves et al., 2013, 2017; Thistlethwaite, 2012). In this regard, process research needs a clear theoretical base to be strong and acknowledged (Olson \& Bialockerkowski; 2014, Reeves, Boet, Zierler \& Kitto, 2015; Reeves et al., 2017; Thistlethwaite, 2012).

However, the knowledge production regarding the effectiveness moves forward in pace with the growth in empirical work (Foreman et al., 2016; Reeves et al., 2016, 2017). Both a recent review (Reeves et al., 2016) and a recent synthesis of reviews (Reeves et al., 2017) confirm and strengthen earlier positive findings. In general, the learners improve their attitudes towards each other and gain knowledge and skills in collaborative practice (Fox et al., 2018; Reeves et al., 2016, 2017). However, these findings mainly rest on the learners' self-reported experiences of changes after participating in IPE (Reeves et al., 2016, 2017).

Individual self-reported experiences need supplementation from direct observations to strengthen the knowledge regarding the interprofessional collaboration investigated and to articulate its complexity (Morgan, Pullon \& McKinlay, 2015, p. 1217). Essential elements in a collaboration may be hidden in individuals self-reports and thus become obscure from our knowledge about effective collaboration (Morgan et al., 2015, p. 1217). A review of observation studies of interprofessional collaboration revealed that favourable physical space configurations and the allocation of frequent time for shared informal conversation were key facilitators for the evolution of shared knowledge creation, shared goals and shared decisionmaking (Morgan, 2015, p. 1218). A study of interprofessional team meetings in primary care settings showed that the clinicians often were not aware that they did not reach the goals of 
the team meetings; i.e., the development of a joint plan, the summarization of the patients' situations and the personal goals and actions (van Dongen et al., 2017). Another study that reported on simulated IPE among volunteer students and clinicians revealed that the students were highly enthusiastic about interactions and learning together with other professions, especially when the students were familiar with each other prior to the learning activity (van Soeren et al., 2011). Furthermore, an assignment to their own professions and training in realistic scenarios followed by debriefing were important (van Soeren et al., 2011).

In policy documents, IPE research, guidelines, reports and textbooks, the concept of teamwork is linked to interprofessional collaboration in health care (CAIPE, 2017; Fox et al., 2018; Frenk et al., 2010; IPEC, 2011; Lairamore et al., 2018; NM of Health and Care Services, 2015; NM of Education, 2012; Reeves, Lewin, Espin \& Zwarenstein, 2010b, Reeves et al., 2017; WHO, 2010). A team is understood as a group of people pursuing a common goal together (CAIPE, 2017) and teamwork as when the people in the group relate themselves to the group, clarify roles, tasks and goals, create interdependence, integrate with each other and take on responsibility for the performance of the group (Reeves et al., 2010b). The elements of teamwork presuppose that fundamental processes of interaction and collaboration are established.

In our research, we sought to explore how these fundamental processes are possible at all. We relied on Lave and Wenger's (1991) sociocultural theory of learning and the concept of Community of Practice. From this perspective, the pursuit of common goals is understood as fundamental in peoples' interactions and potentially evolves into practices (Lave \& Wenger, 1991; Wenger, 1998), i.e., this practice evolves into joint performances that realize the common goal. A practice emerges from the development and learning of the following three 
intertwined relations of coherence among the participants: mutual engagement, joint enterprise, and a shared repertoire (Wenger, 1998). The participants become a Community of Practice, i.e., the owners of the practice (Wenger, 1998). According to the concept of Community of Practice, common goal achievement is highlighted as the product of a unique development and learning process in which the three relations of coherence evolve between the participants in the very process of pursuing the common goal, regardless of what that goal is, why it is pursued, or what elements the performance demands. The concept of Community of Practice is regularly used in IPE interventions and in the organization of interest groups (Barker et al., 2018; Barr, 2013; CAIPE, 2017, Lee \& Meyer, 2011; McLoughlin, Patel, O’Callaghan \& Reeves, 2018; Pratte, Hurtubise, Rivard, Berbari \& Camden, 2018).

In this article, we contribute new knowledge regarding how students develop and learn interprofessional collaboration using the sociocultural theory of learning from Lave and Wenger (1991). We investigated how students who were given the opportunity to shape their own interprofessional collaboration and learning in patient care during a two-week clinical placement in municipal health services negotiated and learned one of the three relations of coherence, i.e., mutual engagement, in patient care. To explore the very processes of achieving interprofessional collaboration in patient care, we relied on the theoretical concept of mutual engagement as described by Wenger (1998). Based on our theoretical understanding of the learning processes, the data collection methods in ethnography inspired our data generation and the practical iterative framework of qualitative data analysis (Srivastava \& Hopwood, 2009) inspired our thematic data analysis. The research question was as follows: 'how does mutual engagement in patient care evolve in students' interprofessional meetings?' We aimed to describe the learning of mutual engagement in patient care in the interprofessional student meetings. 
Here, we restricted our investigation of mutual engagement to the students' interprofessional meetings. The interprofessional student meetings were one of the activities that the students developed to practice interprofessional collaboration when given the opportunity to shape the interprofessional collaboration in patient care themselves. The students established the meetings as a regular and frequent joint activity, and these meetings became the place for exploring the possibility of and confirming other types of joint activities. We defined the interprofessional student meetings as a "site of knowing" (Nicolini, 2011), i.e., a clearing in time and space in which it was possible to observe mutual engagement while it was developed and learned.

\section{Background}

\section{Theoretical framework}

Lave and Wenger (1991) assumed that our actions are the product of prior negotiation and learning processes in which we link what we know with what we do not know to find meaning and form our actions. Thus, the process comes naturally in all the activities in which we engage in everyday life. Such learning is an informal, situational and ongoing process that occurs while we pursue different goals in life (Lave \& Wenger, 1991; Wenger, 1998).

For a practice to develop between several individuals, a mutual engagement, a joint enterprise and a shared repertoire are negotiated and learned by the participants while they pursue the same goal (Wenger, 1998). The actual negotiation and learning process leading to the practice constitute the community's unique learning history (Wenger, 1998). In this article, we explored the negotiations and learning of mutual engagement between students while they developed their interprofessional collaborative practice in patient care. The development of a 
practice requires dense and persistent mutual engagement between participants (Wenger, 1998) who consequently must include each other in what matters (p. 74), i.e., they must engage and respond to each other's actions and establish relationships based on the mutuality of interaction (Wenger, 1998, p. 137). According to Wenger (1998), everything that makes mutual engagement possible, e.g., information, instrumental aspects, the atmosphere, private talk, and even sharing of candies, is essential.

\section{The interprofessional student placement}

In our research, we studied students who were participating in an interprofessional student placement within the municipal health services in the 2014-2015 period. The student volunteers in their fifth year of education in the field of medicine and third year of nursing, occupational therapy or physiotherapy education were distributed into nine groups as follows: one student from each of the four professions was placed into five of the nine groups, and one student from three of the professions was placed into four of the nine groups (Table 1). Each student group participated for one continuous two-week period. All services for the students' placements occurred in rural settings in Northern Norway. General practitioners, nursing staff, physiotherapists and occupational therapists were all part of the health services.

Table 1. Placement characteristics and student distribution. OT= occupational therapy student, $\mathrm{P}=$ physiotherapy student, $\mathrm{M}=$ medical student and $\mathrm{N}=$ nursing student.

\begin{tabular}{|l|l|l|l|}
\hline $\begin{array}{l}\text { Placement } \\
\text { characteristic }\end{array}$ & $\begin{array}{l}\text { Student } \\
\text { distribution } \\
\text { February 2014 }\end{array}$ & $\begin{array}{l}\text { Student } \\
\text { distribution } \\
\text { November 2014 }\end{array}$ & $\begin{array}{l}\text { Student } \\
\text { distribution } \\
\text { February 2015 }\end{array}$ \\
\hline $\begin{array}{l}\text { Geriatric } \\
\text { rehabilitation ward }\end{array}$ & OT, P, M \& N & OT, M \& N & OT, P, M \& N \\
\hline $\begin{array}{l}\text { Intermediate acute } \\
\text { ward }\end{array}$ & P, M \& N & None & None \\
\hline $\begin{array}{l}\text { Nursing home - } \\
\text { short time stays }\end{array}$ & None & OT, M \& N & OT, P, M \& N \\
\hline $\begin{array}{l}\text { Community health } \\
\text { service }\end{array}$ & OT, P, M \& N & OT, M \& N & OT, P, M \& N \\
\hline
\end{tabular}


The facilitator of the IPE placement provided the students the task of interprofessional collaboration in patient care and the opportunity to shape how they did it without any interference or suggestions from the clinical staff (Norbye, 2016). The students determined how to engage in the interprofessional collaboration themselves based on their personal knowledge and experiences at the time. The study programmes offered the students no specific formal prequalifications, guidelines or learning outcomes in interprofessional collaboration before the clinical placement. Furthermore, the students did not know each other in advance.

The student groups received independent responsibilities for delivering relevant health services to a set number of preselected patients with long-term conditions. One preselected staff member in the clinic functioned as an interprofessional coordinator and introduced the students to the health service and the patients, arranged one or two meetings with the student group, served as the contact person for interprofessional questions, and facilitated a summary at the end of the period. Additionally, one preselected staff member from each of the students' professions functioned as a contact person for potential professional questions. The students had to collaborate with and report to the health service and participate in common and regular patient reports and meetings in the clinic.

\section{Methods}

We complemented our sociocultural perspective by investigating the students' activities as they unfolded, while recognizing the activities as accomplishments based on knowledge and learning situated in time and space (Nicolini, 2012; Wenger, 1998). Inspired by the wellfounded and described data collection methods in ethnography, we generated process data by interviewing the students before and after the placement, by observing the students' activities, 
and by initiating informal conversations with the student groups during the placement. We thereafter conducted an interpretative thematic analysis inspired by the practical iterative framework of qualitative data analysis to identify the evolution of the patterns of collaboration in patient care.

\section{Data collection}

During the clinical placement, the first author observed the students' activities as they unfolded in the students' interprofessional meetings and some of the students' activities with patients with a focus on the evolution of patterns of interactions across six student groups. The second author observed the students' interprofessional meetings across three student groups for four to five days during the two-week period, and the fourth author observed one of the interprofessional meetings held by two student groups. The authors recorded their observations in field notes in real time or within an hour after the activity with the goal of creating a rich and close record of the actions. Additionally, the first and second authors initiated informal conversations with the student groups about their activities. Both the students' joint meetings and informal conversations were audio recorded. The authors prepared self-reflexive notes in separate sections of the field notes during the activities.

\section{Data analysis}

The interpretative thematic analysis built on the sound recordings and field notes from the students' interprofessional meetings and informal conversations with the groups. The first author listened to the audio recordings from 26 interprofessional student meetings across student groups and six informal conversations with student groups and read the field notes to become familiar with the content. The second and fourth authors listened to sections of the material, and the first and second authors compared the contents of their separately collected 
material. All four authors contributed to the interpretation and analysis of the data. The analysis moved back and forth between the data, Lave and Wenger's (1991) sociocultural learning theory, and Wenger's (1998) concept of mutual engagement, in a reflexive iterative process that was led by the three questions given by the practical iterative framework of qualitative data analysis (Srivastava \& Hopwood, 2009).

Inspired by the first iterative question, 'what are the data telling us, we asked what are the students doing in the interprofessional meetings? Here, "doing" is understood as both bodily and discursive (Nicolini, 2012). We interpreted the material sentence by sentence and reconstructed it using initial codes. Thereafter, we reconstructed the initial codes into categories of doings across student groups. Inspired by the second iterative question, 'what do we want to know, we then asked what negotiations are occurring in students' doings?' We interpreted the categories of doings and reconstructed the categories into main themes of negotiation. This process resulted in the identification of typical examples of main themes of negotiations across the interprofessional meetings. We then asked the third iterative question, 'what is the dialectic relationship between what the data are telling us and what we want to know?' The students' main actions in the interprofessional meetings seemed to involve negotiations about their present and future collaborations.

Considering the first iterative question, we investigated and interpreted the condensed negotiations by asking two subsequent and contiguous questions based on our search for the development of mutual engagement, i.e., 'what mutual engagement evolves in students' negotiations in interprofessional meetings?', and 'how do the students make mutual engagement possible in the meetings?' We then reconstructed the negotiations into categories of mutual engagement. In relation to the second iterative question, we asked, 'what are the 
relations between the different types of mutual engagement evolving among the students in the interprofessional meetings?' We then reconstructed the categories of mutual engagement into three main types of mutual engagement. Regarding the third iterative question, the students' mutual engagement in patient care appeared to be highly complex.

\section{Ethical considerations}

The Norwegian Social Science Data (NSD) approved this research project in July 2013 (approval number 34895). Furthermore, the Regional Ethics Committee of Medical Research Ethics approved the project in September 2014 (approval number 2014/1659).

\section{Results}

A characteristic of the interprofessional student meetings was the mutual engagement between the students to determine how they could provide good care and treatment to the patients together. The students expressed the following three types of mutual engagement: a) facilitating interactions in patient care, $b$ ) interactions in patient care, and c) clarifying further interactions in patient care. All three types of engagement were observed in the first interprofessional student meeting, and the students continued to engage in the same manner in all later meetings throughout the clinical placement.

The three types of mutual engagement occurred differently in the meetings, and the relationships between the three types were both tight and complex. Type A, facilitating interactions in patient care, ran parallel to Types B and C and appeared to support the two types of engagement. Type B interactions in patient care, were the main theme among the students in the meetings. Type $\mathrm{C}$ interactions, which clarified further interactions in patient care, appeared in sequences and in various degrees during or after Type B engagement. 
Engagement in Type $\mathrm{C}$ interactions supported further interactions between the students after the meetings. We present the three types of engagement below.

\section{Mutual engagement in facilitating interactions in patient care}

A characteristic of the facilitation of interactions in patient care was the active inclusion by the students of one another in the activities in the meeting. The students contributed to this inclusion in three ways. First, the students engaged in creating a good atmosphere in the meetings. The students did this by looking at each other, smiling and using firm and polite voices when they spoke with each other. Even when the students disagreed, they continued to be friendly and polite. The example below is from the meeting of student group 3 on the seventh day of the clinical placement and shows how the students handled disagreement in a friendly manner:

The student group decided earlier to do a home visit with a patient, and the medical student decided not to participate. The occupational therapy student now shares her opinion with the medical student. "I still think you should join us," she says carefully. "I would rather do some other work in the clinic. I do not think I have anything to offer by participating," the medical student answers, friendly but firmly. "I still think it would be important for all of us. We are going to discuss what we observe afterwards," the occupational student answers in a friendly manner. "I will participate in the discussions," the medical student answers, friendly but firmly. The conversation between the students continues in a friendly and polite tone.

Second, the students engaged in sharing their knowledge and thoughts about the patient's health and treatment, one after another. In most student groups, this occurred spontaneously. The students did it by offering or being asked to share their knowledge and thoughts, and the other students took over one by one when the first student had finished. When a conversation about knowledge and meanings appeared while it was shared, the students allowed the person who was sharing to continue sharing when the conversation ended. The example below is from the meeting of student group 2 on the third day of placement and unfolds one of the 
many ways the students offered to share knowledge and allowed each other to finish before taking over:

The physiotherapy student has made a written report after examining one of the patients and now wants to share the findings. The student reports substantial problems in the mapping of the patients' pain because the patient lacked engagement in the issue when asked. The nursing student is then asked to speak with the patient about the issue to fill in. "But I am not sure about what we can expect from the patient; she somehow seems to have given up. However, I can elaborate my thoughts about the patient when it is my turn to share because I suspect that the patient in her situation has several kinds of explanations for what she experiences", says the medical student. "Yes, but we can keep it in our minds," the physiotherapy student answers and the co-students agree. The physiotherapy student continues to report, and the students discuss several aspects about the patients' health condition that were reported before the physiotherapy student finished. Thereafter the medical student takes the initiative to report.

Third, the students engaged in deciding the progression of the meeting and the further patient care together. The students did this by continuously presenting proposals for further activity to each other and waiting for answers before continuing. When the students forgot to formulate an activity as a proposal, they quickly corrected themselves. The example below is from midway through the first meeting of student group 1. The medical student wanted to map the patient's health conditions without formulating the activity as a proposal to the other students. The medical student urgently corrected himself:

"I will perform a full examination of the patient," the medical student says and suddenly stops, looking at the co-students before continuing, "Or I could do it. What do you think about that?" The co-students smile and confirm the proposed examination.

\section{Mutual engagement in patient care}

A characteristic of the interactions in patient care was that the students actively involved themselves and each other professionally to determine what constituted good patient care and treatment. The students contributed to the involvement in three particular ways. First, the students engaged in sharing their own knowledge and thoughts about the patients' health conditions and treatment. The students did this by telling each other what they had read in the 
patient records, what they had heard in reports and when talking with the personnel in the clinic and what they themselves had experienced while working with patients. The example below is from a meeting in student group 6 on the second day in the placement and shows how the students began to evolve a knowledge about a patient by referring to different sources in the ward unit:

The physiotherapy student has received a short oral report from one of the physiotherapists about a patient before any of the students have met him. The student gives a short summary to the co-students while referring to what the physiotherapist has said about the patient's hospitalization. The students discuss the information consecutively while shared. When the physiotherapy student finished the report, the medical student asks humorously, "Do you know what treatment the patient has got here in the ward until today? Or, maybe we have to find out about it ourselves?" "No, I don't know" the physiotherapy student answer and continues, "However, I have also read the DIPS (Distributed Information and Patient data System for hospitals). The patient has not yet tried to climb the stairs, used any walking support or tested his balance." Now the occupational therapy student fills in the information from DIPS, "He has just done the MMS test (Mini Mental Status test) and is going to do the clock test and some more cognitive tests which I am not familiar with tomorrow at a quarter past twelve with the occupational therapist. Thereafter, I will know some more about the patient". The students now begin to share how they want to collect more information about the patients.

Second, the students engaged in expanding on the information they told each other. The students did this by asking questions and starting conversations about what they had been told. The students who were speaking also asked questions and started conversations with their fellow students. The example below is from the beginning of the first meeting of the student group 1. The nursing student shared her thoughts about a patient after participating in morning care and the physiotherapy student initiated a conversation:

"The morning care went well. The patient had slept well and was awake and in good shape. He needed less help than before, they said. One nurse supported him standing upright, and another supported him in front; then, he moved over to the toilet himself," the nursing student said and paused, "Was he guided to the right foot while moving?" the physiotherapy student asks calmly. "I am not sure," the nursing student answers hesitantly and smiles. "Were any instructions given to the patient?" the physiotherapy student asks calmly. "No, nothing was said," the nursing student answers. The two students continue the conversation. The physiotherapy student starts to explain why the patient should be guided and shows the other students how it should be done. The nursing student also clarifies further details. 
A third manner in which the students engaged was by deciding on further activities with patients based on the information provided in the conversations. The students did this both by formulating proposals about further activity and by making decisions together based on the proposals. Occasionally, new information emerged that expanded the conversation when the students assessed the proposals regarding further activity. The example below is from a meeting of student group 2 on the second day of placement. The students sat together and read the patient record:

The physiotherapy student notes that the patient has back pain, is anxious and has tense muscles but no neurological symptoms. The medical student adds that the patient has had severe psychological strain, which can affect the condition. The nursing student adds that the patient should be mobilized because of bedsores. The physiotherapy student answers that the students must determine how the patient is feeling while at the same time focusing positively on the patient's resources. "I can assess the patient's level of function during morning care and try to determine how she is feeling and her attitude to training. Then, I can report to you before you plan the training," the nursing student proposes, looking at the physiotherapy student. The physiotherapy student smiles and answers, "Yes, then I can assess the work load in her training programme". "Yes, and then I will visit the patient later when I have read her papers and have discussed her medical condition with her medical doctor," the medical student says. The co-students nod and say yes.

\section{Mutual engagement in clarifying further interactions in patient care}

A characteristic of clarifying further interactions in patient care was that the students started to invite themselves and each other into further joint activities after deciding upon the single students' further activities with patients. The students did this by proposing a joint activity and planning the joint activity together. Specifically, there were four ways in which the students contributed to further interactions. First, the students engaged in making further interprofessional meetings possible. The students proposed that they could continue meeting and discussed how to make this possible. Then, the students clarified the time and length of the meetings. Furthermore, the students were concerned about the care of patients during their meetings and clarified the transfer of patient care to the personnel in the clinic. The example below describes the first meeting of student group 4 on the second day of placement: 
"Should we meet again by the end of the day to summarize what we have done and plan what to do tomorrow?" the medical student proposes in a friendly way, looking at the other students. "From half past two to three o'clock, maybe? At that time, little is occurring in the clinic," the nursing student proposes. "Then, we will have to report to the nurse who is reporting for the evening shift," the medical student adds. "It is a really good idea," the occupational therapy student says. The medical student nods.

The timescale for the meetings was discussed in later meetings. The example below is from

the same student group on the fourth day:

"The meetings easily take one hour. Perhaps we need more time?" the nursing student says, looking at the other students. "Perhaps we should try to be more effective?" the medical student answers. There is a short pause. "I think one hour is fine. Then, we have time to discuss different matters, such as the wound you wanted to discuss today," the occupational therapy student says, looking at the nursing student. "I agree," the medical student answers firmly. The nursing student nods.

Second, the students engaged in performing professional activities with patients together. The students did this by expressing an interest in observing their co-students' professional performances or showing their professional performances to the co-students and by expressing an interest in performing the professional tasks together based on similar or complementary competencies. After expressing their interest, the students planned a time. The example below is from student group 1 and is a continuation of the example above in which the nursing student and the physiotherapy student discussed the mobilization of the patient. The physiotherapy student invited the nursing student to the examination that the student was going to perform on the patient by inviting herself to one of the nursing student's activities with the patient:

The nursing student and the physiotherapy student have just conversed about the mobilization of the patient. Afterwards, the physiotherapy student expresses uncertainty about the necessity of guiding the patient because it seems that this was not done during morning care. The students agree that the physiotherapy student should assess the patient's need for guidance. "I could follow you the next time you help the patient on the toilet. Then, we can assess how the patient is doing it together?" the physiotherapy student proposes in a friendly way, smiling at the nursing student. "Yes, let's do that! I will tell you when it is time. It will probably happen just before lunch," the nursing student answers, smiling. 
Third, the students engaged in confirming the student group as an integral acting unit. The students did this by referring to the group as "we" when summarizing and planning activities between their meetings. In some of the meetings, the students confirmed the group as an integral acting unit by writing a shared work log or working plan that summarized what had been done and what remained to do. The students checked the written log and planned while summarizing the activities during the meetings.

Fourth, the students engaged in making it possible to meet with two or more students in different single activities in patient work. The activities could be meetings with personnel in the clinic who had expertise that the student group was lacking, preparations for presentations at regular clinic meetings, or documentation of the work with patients in the health services documentation system. The students did this by proposing and clarifying who was going to participate.

\section{Discussion}

A practice develops by mutual engagement, a joint enterprise and a shared repertoire that is negotiated and learned by the participants (Wenger, 1998). Therefore, each practice contains a story about how each of these three dimensions develops (Wenger, 1998). By analysing our data based on a general understanding that practices are established in this manner and specifically pursuing the dimension of mutual engagement, we were able to identify in the interactions between the students the emergence of the type of mutuality Wenger (1998) describes as fundamental in practices. In this article, we answered the research question, 'how does mutual engagement in patient care evolve in students' interprofessional meetings?' by telling the story of how mutual engagement in patient care is negotiated and learned between 
students who are given the opportunity to shape their interprofessional collaboration and learning themselves.

The development and maintenance of a practice requires dense and sustained mutual engagement between participants (Wenger, 1998). Such engagement emerges by the participants' inclusion of each other in what matters, engagement and responding to each other's actions and establishing relationships in which this type of mutuality is the basis of interaction (Wenger, 1998, p. 137). van Soeren et al. (2011) indicates that students' enthusiasm and immersion in interprofessional learning activities rests in the students' willingness to learn and participate in IPE, which is a key learner characteristic in IPE (Reeves et al., 2016). In our data, we found that the students already included each other in patient care in the first interprofessional meeting through a highly complex mutual engagement, and they continued to relate to each other in the same complex manner in further meetings. The students spontaneously and intuitively developed mutuality in patient care between themselves, as they immediately created a space in which they could talk with each other about patient care during the first interprofessional meeting. According to Morgan et al. (2015), physical space configurations and frequent times for communication are key facilitators for the evolution of shared knowledge, shared goals and shared decision-making in interprofessional collaboration. In our material, the students continued to create the same space for talking together throughout the placement. The students created this space because they, as a group, were tasked with the responsibility of delivering relevant health care to preselected patients but received no guidelines on how to do this. The students participated in the interprofessional meetings to determine how to deliver care to these patients. van Soeren et al. (2011) indicates that assigning students to their own profession in IPE allows the student to use their fresh professional knowledge and grow their self-awareness and professional 
identity (p. 439). Additionally, the realistic learning activities and environments motivate the students (Reeves et al., 2016; van Soeren et al., 2011) because the students are able to discover a manageable gap between their current knowledge and the desired knowledge (van Soeren et al., 2011, p. 438). According to Wenger (1998), we as humans connect what we know with what we do not know when we develop actions. This action was performed by the students when they linked their previous knowledge and experience to the situation and formulated proposals about how to interact and made assessments and decisions regarding how to interact during the first interprofessional student meeting. By working together, including involving and inviting each other and themselves into activities in the meetings, the students learned what type of mutuality they should apply to their work.

When the students met for their first interprofessional meeting, they spontaneously and intuitively created a comprehensive and inclusive structure and atmosphere that helped all the students participate at all times in the meetings. Even when the students disagreed in one case, they treated each other with great respect. In the first meetings, the students were very careful and tentative in relation to each other to make space for each other and to make sure that the speaker had finished speaking. Therefore, the pace of the first meetings was slow. This is how the students negotiated and learned to be interactive partners while still not knowing each other very well. Nevertheless, this early development in the student group's mutuality made it possible for the students to quickly begin to engage in interprofessional decision-making in patient care. Thus, the students used the placement period well. However, van Soeren et al. (2011) found that students who are familiar with each other prior to simulation activities immerse themselves more readily into the scenarios and are more comfortable and improvisational. Therefore, it is possible that the students could have begun the interactions in patient care more quickly if the students had the opportunity to get to know each other and the 
department before starting the placement. In this manner, the first days of the placement could have been more efficient, and the length of the placement could have been shorter.

Debriefing is important in realistic scenarios in IPE (van Soeren et al., 2011). However, the students were given no debriefing after their group meetings. Instead, the choice to meet as a joint student group was spontaneously supported by the interprofessional coordinator and personnel at the health service. This occurred by responding positively to the students' choice, informing them about possible available rooms for the meetings and taking on responsibility for the students' patients while the students conducted the meetings. Additionally, the students had to report the patients' treatments, as did the personnel in the health service. In this manner, the health service ensured that the patients received the proper treatment. The students also received inquiries from the management of the health service and researchers throughout the placement period. In this manner, the students received substantial attention to their actions as an interprofessional group. This may have contributed to the students taking on the major responsibility that they were assigned as a group and working together to fulfil it.

IPE is understood as when learners from two or more professional groups learn interactively together to improve collaboration and patient care (WHO, 2010). Therefore, mutuality is a prerequisite for interprofessional interactions. According to Wenger (1998), the mutuality that applies to any practice must be negotiated and learned among the participants. Based on our findings, it appears that the students' natural meaning-seeking processes are initiated when they are organized in interprofessional student groups that are responsible for delivering relevant health care to real patients and by being supported in spending time to determine what to do together. The students then have time to use previous knowledge and experience to 
determine how to engage as an interprofessional group to make interactions with patients work. The students' natural negotiation and learning process are thereby exploited, and the students develop an intimate understanding and ownership of the mutuality of the student group. Based on our findings, we understand that the mutuality that the students developed are the same as Wenger's (1998) description of constituents of a practice. However, we do not mean that the students developed a complete practice; rather the students began to relate to each other in a manner that might be the first emergence of a practice.

For a comprehensive understanding of IPE and the effectiveness of various IPE arrangements, we need insights into how students learn IPE in addition to what they learn (Olson \& Bialocerkowski, 2014; Reeves et al., 2017; Thistlethwaite, 2012). Such process research must be founded in theory so that the basis for the findings becomes visible (Olson \& Bialocerkowski, 2014; Reeves et al., 2015, 2017; Thistlethwaite, 2012). By basing our research on sociocultural theory learning and Wengers' (1998) concept of mutual engagement, we showed how students shaping their own collaboration and learning develop complex mutuality in their interactions in patient care and how the IPE arrangement supports their natural learning process. Our findings contribute to research about both what is learned and how it is learned by showing that both mutual engagement and the complexity of the engagement are observable as they unfold. Furthermore, it is difficult to report the full complexity of the evolving mutuality at the end of the placement; as if that were the preferred method for investigating mutuality among the students. We have also shown how the components of the IPE arrangement affected the development of mutuality among the students participating in the IPE intervention. The components might be transferrable to other IPE programmes. Our description of students' learning of mutuality is not clear in other IPE research. 
In relation to the study limitations, the students voluntarily participated in this project, which might bias the results because the students had special positive views about and were motivated to engage in interprofessional collaboration. Furthermore, some students openly expressed a feeling of exclusivity through their participation in the intervention and being a subject of research. Other students expressed an experience of increased reflections about their actions when the researcher asked them questions. The presence of the researcher might have positively influenced the students' motivation and execution of collaboration. As O'Reilly (2012) emphasized, the researcher is an active participant in the social life that unfolds while he/she applies data generation and construction methods. Furthermore, the interprofessional coordinator and personnel in the clinic encouraged the students' interprofessional engagement in the clinic, which potentially affected students' motivation to engage in interprofessional collaboration.

Nevertheless, the students had no specific prequalifications before placement, and no guidelines and no formal assessments were applied to complete at the end of the placement that might have informed or motivated their actions throughout the placement. Therefore, the actual mutual engagement that evolved and was maintained in the students' interactions in their interprofessional meetings emerged due to the students' responses to their situation.

\section{Concluding comments}

Complex mutual engagement in patient care evolved and was maintained in the students' interprofessional meetings when the students were given the opportunity to shape their own collaboration and learning in clinical placement. The students' mutual engagement corresponded to the type of mutual engagement that constitutes a practice, as explained by 
Wenger (1998). We asked the question 'how does mutual engagement in patient care evolve in students ' interprofessional meetings?' The students who shaped their own collaboration and learning learned mutuality in patient care by receiving the opportunity to create a space for negotiation regarding how to provide good care to the patient as a group.

We interpreted the students' own natural learning process while developing mutuality as a self-produced reaction to the trust that they were given. Mutual engagement is of critical importance in interprofessional collaboration. Correspondingly, IPE must develop students' mutual engagement by delivering learning arrangements that support such learning. The IPE arrangement in which the students' participated supported the students' natural learning processes. Lave and Wenger's (1991) sociocultural learning theory and the concept of mutual engagement (Wenger, 1998) allowed us to observe and describe the three types of mutual engagement that are necessary for this collaborative practice to be established in student groups.

\section{Declaration of interest}

The authors report no conflicts of interest. The authors alone are responsible for the content and writing of this article.

\section{References}

Baker, M., Lecce, J., Ivanova, A., Zawertailo, L., Dragonetti, R. \& Selby, P. (2018). Interprofessional Communities of Practice in Continuing Medical Education for Promoting and Sustaining Practice Change: A Prospective Cohort Study. The Journal of Continuing Education in the Health Professions, 38(2): published ahead of print. doi: 10.1097/CEH.0000000000000191

Barr, H. (2013). Toward a theoretical framework in interprofessional education. Journal of Interprofessional Care, 27: 4-9. doi: 10.3109/13561820.2012. 698328

CAIPE. (2017). Interprofessional Education Guidelines 2017. Fareham, United Kingdom: CAIPE. 
CAIPE. (2010). Introducing Interprofessional Education. Fareham, United Kingdom: CAIPE.

Foreman, D., Jones, M. \& Thistlethwaite, J. (Ed.). (2016). Leading Research and Evaluation in Interprofessional Education and Collaborative Practice. London: Palgrave Macmillan Publishers Ltd.

Fox, L., Onders, R., Hermansen-Kobulnicky, C., Nguyen, T., Myran, L., Linn, B. \& Hornecker J. (2018). Teaching interprofessional teamwork skills to health professional students: A scoping review. Journal of Interprofessional Care, 32(2): 127-135. doi: 10.1080/13561820.2017.1399868

Frenk, J., Chen, L., Bhutta, Z., Cohen, J., Crisp, N., Evans, T., ... Zurayk, H. (2010). Health professionals for a new century: transforming education to strengthen health systems in an interdependent world. The Lancet, 376:1923-58. doi: 10.1016/S01406736(10)61854-5

IPEC. (2011). Core Competencies for Interprofessional Collaborative Practice. Report from an Expert Panel.

Lave, J. \& Wenger, E. (1991). Situated learning. Legitimate Peripheral Participation. Cambridge: Cambridge University Press.

Lee A. \& Meyer, E. (2011). Theoretically speaking: use of communities of practice framework to describe and evaluate interprofessional education. Journal of Interprofessional Care, 25: 84-90. doi: 10.3109/13561820.2010.515429

Lairamore, C., Morris, D., Schichtl, R., George-Paschal, L., Martens, H., Maragakis, A., ... Bruenger, A. (2018). Impact of team composition on student perceptions of interprofessional teamwork: A 6-year cohort study. Journal of Interprofessional Care, 32(2): 143-150. doi: 10.1080/13561820.2017.1366895

McLoughlin, C., Patel, K., O’Challaghan, T \& Reeves, S. (2018). The use of communities of practice to improve interprofessional collaboration and education: findings from an integrated review. Journal of Interprofessional Care, 32(2): 136-142.

Ministry of Education. (2012). Education for welfare (Utdanning for velferd), Report to the Storting no 13 (2011-2012).

Ministry of Health and Care Services. (2015). National health- and hospital plan (20162019). (Nasjonal helse- og sykehusplan, 2016-2019), Report to the Storting no 11 (2015-2016).

Morgan, s., Pullon, S. \& McKinlay, E. (2015). Observation of interprofessional collaborative practice in primary care teams: An integrative literature review. International Journal of Nursing Studies, 52: 1217-1230. doi: 10.1016lj.ijnurstu.2015.03.008

Nicolini, D. (2011). Practice as the site of knowing: Insights from the field of telemedicine. Organization Science, 22(3): 602-620. doi:10.1287/orsc.1100.0556 
Nicolini, D. (2012). Practice theory, work, and organization. Oxford: Oxford University Press.

Norbye, B. (2016). Healthcare students as innovative partners in the development of future health care services: An action research approach. Nurse Education Today, 46, 4-9. doi: 10.1016/j.nedt.2016.06.021

Olson, R. \& Bialocerkowski, A. (2014). Interprofessional education in allied health: a systematic review. Medical Education, 48, 236-246. doi:10.1111/medu.12290

O’Reilly, K. (2012). Ethnographic methods. New York: Routledge.

Pratte, G., Hurtubise, K., Rivard, L., Berbari, J. \& Camden, C. (2018). Developing a Web Platform to Support a Community of Practice: A Mixed Methods Study in Pediatric Physiotherapy. Journal of Continuing Education in Health Professions, 38(1): 19-24. doi: 10.1097/CEH.0000000000000185

Reeves, S. \& Pauzé, E. (2010a). Examining the effects of interprofessional education on mental health providers: Findings from an updated systematic review. Journal of Mental Health, 19(3): 258-271. doi: 10.3109/09638230903469244

Reeves, S., Lewin, S., Espin, S. \& Zwarenstein, M. (2010b). Interprofessional Teamwork for Health and Social Care. Wiley-Blackwell

Reeves, S., Perrier, L., Goldman, J., Freeth, D. \& Zwarenstein, M. (2013). Interprofessional education: Effects on professional practice and healthcare outcomes (update). The Cochrane Library. doi: 10.1002/14651858.CD002213.pub3

Reeves, S., Boet, S., Zierler, B. \& Kitto, S. (2015). Interprofessional Education and Practice Guide No. 3: Evaluating interprofessional education. Journal of Interprofessional Care, 29(4): 305-312. doi: 10.3109/13561820.2014.1003637

Reeves, S., Fletcher, S., Barr, H., Birch, I., Boet, S., Davies, N., ... Kitto, S. (2016). A BEME systematic review of the effects of interprofessional education: BEME Guide No. 39. Medical Teacher, 38(7): 656-668. doi: 10.3109/ 0142159X.2016.1173663

Reeves, S., Palaganas, J \& Zierler, B. (2017). An Update Synthesis of Review Evidence of Interprofessional Education. Journal of Allied Health, 46(1): 56-61.

Srivastava, P. \& Hopwood, N. (2009). A practical iterative framework for qualitative data analysis. International Journal of Qualitative Methods, Open Access.

Thistlethwaite, J. (2012). Interprofessional education: A review of context, learning and the research agenda. Medical Education, 46, 58-70. doi:10.1111/j.1365-

2923.2011.04143.x

van Dongen, J., van Bokhoven, M., Daniëls, R., Lenzen, S., van der Weijden, T. \& Beurskens, A. (2017). Interprofessional primary care team meetings: a qualitative approach comparing observations with personal opinions. Family Practice, 34(1): 98106. doi: 10.1093/fampra/cmw106 
van Soeren, M., Devlin-Cop, S., MacMillan, K., Baker, L., Egan-Lee, E. \& Reeves, s. (2011). Simulated interprofessional education: An analysis of teaching and learning processes. Journal of Interprofessional Care, 25:6, 434-440. doi: $10.3109 / 13561820.2011 .592229$

Wenger, E. (1998). Communities of Practice; Learning, meaning and identity. Cambridge: Cambridge University Press.

World Health Organization. (2010). A WHO Report: Framework for Action on Interprofessional Education \& Collaborative Practice (00907421). Retrieved from Washington: WHO. 